\title{
Reversible dementia and gait disturbance as a result of polypharmacy
}

\author{
Monica Gupta, Ram Singh, Kamal Singh, S S Lehl
}

Department of Medicine, Government Medical College and Hospital, Chandigarh, India

\section{Correspondence to}

Dr Monica Gupta, monicamanish2001@gmail. com

\section{DESCRIPTION}

A 53-year-old man presented with gradually progressive difficulty in walking, excessive lethargy and forgetfulness of 3 months duration. There was a noticeable decrease in verbal spontaneity, initiative and occasional episodes of urinary incontinence. Treatment records revealed that patient was consulting three different specialists for his multiple comorbidities such as painful diabetic neuropathy, hypertension and insomnia. His medication pills were retrieved and it was ascertained that he was consuming amitryptiline and carbamazipine for last 4 years. Recently pregabalin along with escitalopram had been added to the regimen, that is, around 3 months previously, which corresponded with the onset of this neurological worsening. On examination, mini mental state examination (MMSE) score was 20/30 and his gait was broad based, shuffling with difficulty in turning. The timed get up and go score was $34 \mathrm{~s}$. Sensory examination revealed bilateral distal symmetrical sensory motor neuropathy. Fundus showed bilateral mild non-proliferative diabetic retinopathy, no papilloedema.

Brain MRI (figure 1) showed prominent ventricular enlargement out of proportion to sulcal

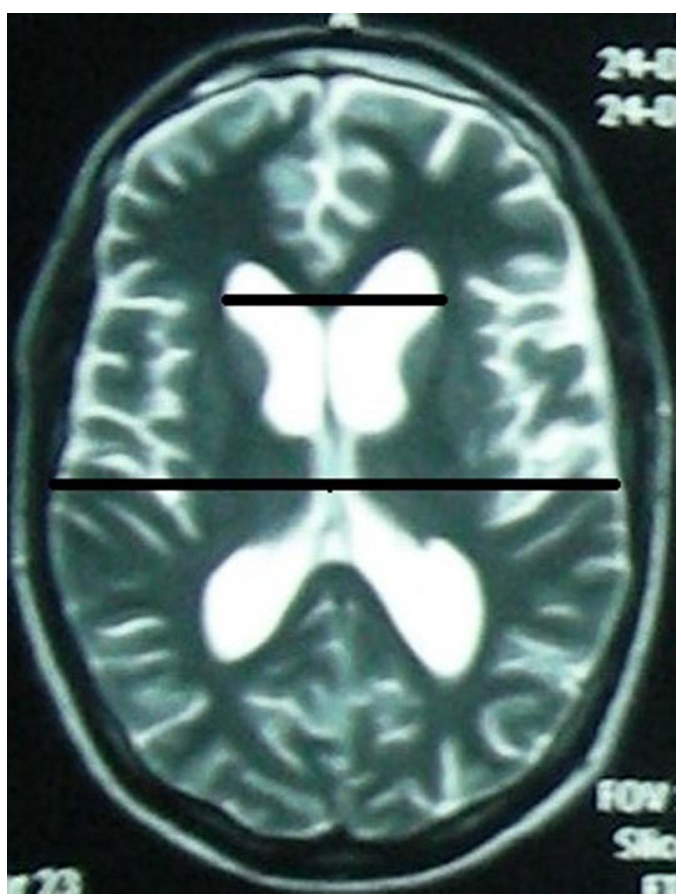

Figure 1 T2-weighted MRI of the brain depicting prominent ventricular enlargement out of proportion to sulcal atrophy, rounded frontal horn, temporal horn enlargement, periventricular signal changes and Evan's index of more than 0.3 suggestive of normal pressure hydrocephalus (NPH). atrophy, rounded frontal horn, temporal horn enlargement, periventricular signal changes and an Evan's index of more than 0.3 suggestive of normal pressure hydrocephalus (NPH). Patient underwent diagnostic lumbar puncture to rule out infection. The cerebrospinal fluid opening pressure was normal. Pregabalin and escitalopram were withdrawn from the treatment schedule. A follow-up of 6 months has shown consistent improvement in gait (timed get up and go score improved by $15 \mathrm{~s}$ ) and cognitive functions.

NPH is a potentially reversible cause of dementia in elderly and this case highlights polypharmacy as its most likely cause due to its temporal relation. Reversible dementia and gait disturbance with valproic acid, hydrocephalus during natalizumab treatment and development of communicating hydrocephalus after infliximab infusion are similar recent reports. ${ }^{1-3}$

Approximately 50\% cases of NPH are idiopathic. A wide variety of conditions mimic the symptomatology of NPH such as depression, Alzheimer disease, Parkinson disease, multi-infarct dementia, frontotemporal dementia, Lewy body disease and corticobasal degeneration. These conditions can be definitely excluded by the characteristic imaging findings of NPH. Sulcal atrophy especially prominent medial temporal cortical atrophy (Alzheimer disease) and significant white matter ischaemic disease (vascular dementia) favours a diagnosis of hydrocephalus ex vacuo.

\section{Learning points}

- Physicians must always be alert to the adverse effects of polypharmacy in patients with multiple diagnosis and multiple prescriptions.

- The implications of polypharmacy are huge considering the rising number of young elderly with dementia syndromes and the diagnosis of such a reversible aetiology is rewarding.

- There is a desperate need to develop a comprehensive geriatric assessment so that a distressed patient does not fall in the trap of polypharmacy and its complications.

Competing interests None.

Patient consent Obtained.

Provenance and peer review Not commissioned; externally peer reviewed. 


\section{REFERENCES}

1 Evans MD, Shinar R, Yaari R. Reversible dementia and gait disturbance after prolonged use of valproic acid. Seizure 2011;20:509-11.
2 Zecca C, Städler C, Gobbi C. Hydrocephalus during natalizumab treatment. Neurol Sci 2010;31:635-7.

3 Maclennan A, Long MD, Herfarth $\mathrm{HH}$. Development of communicating hydrocephalus after infliximab Infusion. Inflamm Bowel Dis 2011;17:E2-E3.

Copyright 2013 BMJ Publishing Group. All rights reserved. For permission to reuse any of this content visit http://group.bmj.com/group/rights-licensing/permissions.

BMJ Case Report Fellows may re-use this article for personal use and teaching without any further permission.

Become a Fellow of BMJ Case Reports today and you can:

- Submit as many cases as you like

- Enjoy fast sympathetic peer review and rapid publication of accepted articles

- Access all the published articles

- Re-use any of the published material for personal use and teaching without further permission

For information on Institutional Fellowships contact consortiasales@bmjgroup.com

Visit casereports.bmj.com for more articles like this and to become a Fellow 